\title{
Greenhouse and Field Evaluations of Entomopathogenic Nematodes (Nematoda: Heterorhabditidae and Steinernematidae) for Control of Cabbage Maggot (Diptera: Anthomyiidae) on Cabbage
}

\author{
PETER C. SCHROEDER, ${ }^{1}$ CAROL S. FERGUSON, ${ }^{1}$ ANTHONY M. SHELTON, \\ WILLIAM T. WILSEY, MICHAEL P. HOFFMANN, ${ }^{2}$ AND CURTIS PETZOLDT ${ }^{3}$ \\ Department of Entomology, Comell University, New York State Agricultural Experiment Station, \\ Geneva, NY 14456
}

\begin{abstract}
J. Econ. Entomol. 89(5): 1109-1115 (1996)
ABSTRACT Entomopathogenic nematodes-Heterorhabditis bacteriophora Poinar (Oswego strain), Steinernema carpocapsae (Weiser) (NY001 strain), Steinernema carpocapsae (25 strain), Steinernema feltiae Filipjev (=Neoaplectana carpocapsae Weiser) (369 strain), Steinernema feltiae (27 strain), and Steinernema riobravus Cabanillas and Poinar (355 strain) -were examined for pathogenicity against cabbage maggot, Delia radicum (L.), larvae in the greenhouse and field. Applications (per plant) of 3,000 and 4,000 infective juveniles of S. feltiae (369 strain), 30,000 infective juveniles of $H$. bacteriophora (Oswego strain), and 300 and 30,000 infective juveniles of $S$. feltiae (27 strain) reduced the number of $D$. radicum that developed to pupae on potted cabbage plants. H. bacteriophora (Oswego) at applications of 3,000 and 30,000 infective juveniles per plant and $S$. feltiae ( 27 strain) at applications of 30,000 (but not 3,000) infective juveniles per plant significantly reduced root damage caused by larvae of $D$. radicum. Logarithmically increased dosages between 100 and 100,000 infective juveniles per plant of $S$. feltiae ( 27 strain) linearly reduced the number of $D$. radicum pupae that developed on potted cabbage plants and the damage caused to the roots by $D$. radicum larvae. Root and stem dry weights of cabbage plants infested with $D$. radicum were significantly greater for plants inoculated with 100,000 infective juveniles of $S$. feltiae (27 strain) than for plants not inoculated with nematodes. Nematode inoculation did not prevent significant losses in root or stem dry weights at dosages less than 100,000 infective juveniles per plant. Soil surface applications of 100,000 and 200,000 infective juveniles per plant of $S$. feltiae ( 27 strain) were more effective than subsurface applications in preventing damage by natural or augmented populations of $D$. radicum larvae on cabbage in the field. However, mortality rates of wax moth larvae exposed to soil samples treated with $S$. feltiae (27 strain) suggested that this nematode showed greater persistence when applied beneath rather than on the soil surface.
\end{abstract}

KEY WORDS Delia radicum, Brassica oleracea, entomopathogenic nematodes

THE CABBAGE MAGGoT, Delia radicum (L.), damages Brassica crops, including cabbage, Brassica oleracea $(\mathrm{L}$.$) , grown in the temperate zone of the$ Holarctic regions of the world. In New York state, insecticides provide an adequate defense against $D$. radicum populations during the plant growth stages before precupping when damage would cause the greatest reduction in yield (Andaloro et al. 1983). However, researchers are seeking alternatives to the use of insecticides because of the demonstrated impact of insecticides on natural en-

\footnotetext{
${ }^{1}$ Current address: Biology Department, Southem Oregon State College, Ashland, OR 97520 .

${ }^{2}$ Current address: Department of Entomology, Cornell University, Ithaca, NY 14853 .

${ }^{3}$ Current address: IPM Programs, New York State Agricultural Experiment Station, Cornell University, Geneva, NY 14456
}

emies of insects, the potential adverse effect of insecticides on the environment, and the likelihood that targeted insects will develop resistance to insecticides that are repeatedly or frequently used. Physical barriers (Matthews-Gehringer and Hough-Goldstein 1988), insect growth regulators (Young et al. 1987, Gordon et al. 1989), field sanitation, and the adjustment of planting dates have been tried with limited success. However, because of prohibitive costs or labor requirements, most growers have avoided these practices.

Recent advances in development of methods for producing, storing, and applying entomopathogenic nematodes have decreased the cost and increased the effectiveness of using these organisms for controlling many soil insect pests (Kaya and Gaugler 1993). Entomopathogenic nematodes 
have been shown to reduce numbers of $D$. radicum larvae on various crucifers (Welch and Briand 1961, Georgis et al. 1983, Simser 1992). Here we report the results of greenhouse experiments that investigated the effectiveness of 6 species or strains of nematodes to prevent damage caused by $D$. radicum larvae to cabbage. Also, we report the effectiveness of nematodes applied below and on the soil surface in a cabbage field containing augmented and natural populations of $D$. radicum larvae.

\section{Materials and Methods}

Greenhouse Experiments. Four greenhouse experiments were conducted on the New York State Agricultural Experiment Station campus. Cabbage, 'Little Rock,' was started in individual cell trays, then transplanted after 4 wk to $10-\mathrm{cm}$ plastic pots containing a 3:1:1 mixture of sandy loam (sieved to remove rocks and gravel $>0.6 \mathrm{~mm}$ diameter): Cornell Mix (1:2 peat moss:vermiculite mixture):sand. The greenhouse was maintained at $21 \pm 10^{\circ} \mathrm{C}$ and $60 \pm 30 \% \mathrm{RH}$ and contained four 1,500-W metal halide lamps (photoperiod of $16: 8$ [L:D] h) that supplemented natural light. Plants were watered daily and fed weekly with 16:32:16 (N:P:K) fertilizer. Plants were infested with $D$. radicum larvae by placing 0 - to 4 -d old eggs onto filter paper, then washing the eggs onto the soil surface next to the stem of each plant. Eggs of $D$. radicum were collected from adult flies reared on turnip at $21^{\circ} \mathrm{C}, 60 \% \mathrm{RH}$, and a photoperiod of $16: 8$ (L:D) $h$. On the same day the plants were infested with $D$. radicum, plants were inoculated with entomopathogenic nematodes by first suspending the nematodes in $200-500 \mathrm{ml}$ of water then applying $1-5 \mathrm{ml}$, depending on the intended nematode concentration (determined by serial dilution), of the nematode suspension next to the stem of each plant. All plants were then watered to saturation by a hand-held sprinkler. Nematodes-Steinemema carpocapsae (25 strain), Steinernema feltiae ( 27 strain), Steinernema feltiae (369 strain), Steinernema riobravus (355 strain)-were obtained from a commercial supplier (Biosys, Columbia, MD) $\approx 1$ wk before each experiment, or, nematodes-Steinernema carpocapsae (NY001 strain) and Heterorhabditis bacteriophora (Oswego strain) originally isolated from New York state in 1990 (Schroeder et al. 1994)-were reared using greater wax moth larvae, Galleria mellonella (L.) (Ja-Da Bait, Antigo, WI). The effectiveness of a nematode treatment was evaluated by counting the number of $D$. radicum that reached 3rd instar or pupation on cabbage plants, and scoring the roots of the cabbage plants based on the amount of damage caused by the larvae of $D$. radicum. Larvae and pupae of $D$. radicum were recovered from the pots by washing the soil through a 2-mm screen. Root injury was scored for each plant, then converted to a root damage index (RDI) (Dapsis and Ferro 1982). In- dividual root damage scores were $0(\mathrm{RDI}=0)$, no visible injury present; 1 (RDI $=25$ ), superficial feeding scars present (no wounds reaching the root cortex); 2 (RDI $=50$ ), deep scars or wounds present but tap root intact; 3 (RDI $=75$ ), tap root severed or girdled but plant alive; and 4 (RDI $=$ 100), plant dead. Although root damage index values do not directly compare with plant loss (and therefore crop yield), the index discriminated between treatment effects better than plant counts and provided a direct measure of plant injury (Dapsis and Ferro 1982).

Because mean $D$. radicum larvae and pupae counts were roughly proportional to their standard deviations, counts were transformed $[\log (y+1)]$ before statistical analysis. Transformed counts of D. radicum larvae and pupae and computed root damage indices (no transformation needed) were analyzed for treatment differences using analysis of variance (ANOVA) (SYSTAT 1992). When the ANOVA revealed a significant treatment effect, treatment means were separated using the Fisher least significant difference (LSD) test (SYSTAT 1992). Experimental design and protocol for each greenhouse experiment was as described below.

Experiment 1. Cabbage was planted the week of 1 September 1993 and transplanted on 27 October 1993. On 8 November 1993, individual plants (5- to 6-leaf stage) were infested with 5 eggs of $D$. radicum (except plants designated as uninfested controls [i.e., no D. radicum treatment]) and inoculated (except plants designated as uninocnlated controls [i.e., no nematode treatment]) with 4,000 infective juveniles of either $S$. carpocapsae (25 strain), S. carpocapsae (NY001 strain), H. bacteriophora (Oswego strain), S. feltiae (369 strain), or S. riobravus (355 strain). Each treatment (uninfested control, uninoculated control, plus 5 nematode treatments) was replicated 5 times and arranged in a completely randomized block design. On 6 December 1993, five plants from each treatment were sampled in each block (i.e., 5 plants $\times$ 7 treatments $\times 5$ blocks $=175$ pots). Pots were sampled for larvae and pupae of $D$. radicum but roots were not rated for injury. Because uninfested plants hosted no $D$. radicum larvae and cursory inspection of the roots revealed no apparent scarring that could be confused with $D$. radicum feeding, uninfested controls (but not uninoculated controls) were eliminated from the analysis of this and subsequent greenhouse experiments.

Experiment 2. Cabbage was planted 4 November 1993, then transplanted on 3 January 1994. On 13 January 1994, individual plants (5- to 6-leaf stage) were infested with 5 eggs of $D$. radicum and inoculated (except for uninoculated controls) with 3,000 infective juveniles of either $S$. carpocapsae (NY001 strain), H. bacteriophora (Oswego strain), S. feltiae (369 strain), or $S$. riobravus (355 strain). Each nematode treatment and the uninoculated control was replicated 5 times and arranged in a completely randomized block design. Each block 
contained 5 plants of each treatment (i,e., 5 plants $\times 5$ treatments $\times 6$ blocks $=150$ pots). On 10 and 11 February 1994, pots were sampled for larvae and pupae of $D$. radicum and the root of each plant was rated for injury.

Experiment 3. Cabbage was planted 11 January 1994, then transplanted on 11 February 1994. On 11 February 1994, individual plants (5- to 6-leaf stage) were infested with 8 eggs of $D$. radicum and inoculated (except for uninoculated controls) with 3,000 or 30,000 infective juveniles of $S$. carpocapsae (NY001 strain), H. bacteriophora (Oswego strain), or S. feltiae (27 strain). Treatments were replicated 6 times and arranged in a completely randomized block design. Each block contained 5 plants of each treatment (i.e., 5 plants $\times 7$ treatments $\times 6$ replications $=210$ pots $)$. Between 11 and 15 March 1994, pots were sampled for larvae and pupae of $D$. radicum and roots were rated for injury.

Experiment 4. Cabbage was planted 7 February 1994, then transplanted on 4 March 1994. On 15 March 1994, individual plants (5- to 6-leaf stage) were infested with 8 eggs of $D$. radicum and inoculated with 0 (uninoculated control), 100, $1,000,10,000$, or 100,000 infective juveniles of $S$. feltiae (27 strain). Treatments were replicated 3 times and arranged in a completely randomized block design. Each block contained 15 plants of each treatment (i.e., 15 plants $\times 5$ treatments $\times 3$ blocks $=225$ pots). Between 12 and 14 April 1994, pots were sampled for larvae and pupae of $D$. radicum and roots were washed free of soil and rated for injury. Roots and stems of each plant were severed at the epicotyl. Plant organs were then dried to a constant weight in a forced draft oven set at $43^{\circ} \mathrm{C}$ and weighed.

Field Experiment. A single field experiment was conducted on the New York State Agricultural Experiment Station Fruit and Vegetable Crops Research Farm. Cabbage (2- to 3-leaf stage), 'Cheers', were transplanted on 5 July 1994 to a field plot ( 31 by $31 \mathrm{~m}$ ) containing a Honeyoye silt loam soil using a 2-row mechanical transplanter. Plants were spaced $91 \mathrm{~cm}$ apart between rows and $46 \mathrm{~cm}$ apart within rows. The experiment was split into subplots based on the method of nematode application: soil subsurface application and soil surface application. Rows of plants receiving subsurface applications of nematodes were alternated with rows of plants receiving surface application of nematodes. To prevent the possible movement of nematodes between treated plants, each row of plants that received nematode applications (treatment block) was separated by a row of plants containing untreated plants. In addition, treated plants were separated from other treated plants within a row by treating every other plant within the row. In subplots receiving subsurface applications of nematodes, plants (5- to 6-leaves) were removed from the soil with about a $10-\mathrm{cm}$ ball of soil around the root. A nematode suspension containing 200 $\mathrm{ml}$ of tap water and either $0,30,000,100,000$, or 200,000 infective juveniles of $S$. feltiae (27 strain) was then poured into the transplant hole and the plant replaced in the hole. After firmly tamping the soil around the base of the plant, each plant was thoroughly watered overhead with tap water using a watering can. In subplots receiving surface applications of nematodes, suspensions were applied to each plant ( 7 - to 8 -leaf stage) by slowly pouring (so no runoff occurred) the suspension around the base of each plant. Suspensions contained the same volume and concentrations of nematodes as the subplots receiving subsurface applications. Nematodes were applied in the afternoon in both subplots but $1 \mathrm{wk}$ apart: 14 July, subsurface applications; 21 July, surface applications. Soil was moistened before nematode application either by rainfall the previous afternoon (subsurface applications) or by drenching each plant with $\approx 0.5$ liters of tap water in the morning and early afternoon of the same day (surface applications). Treatments were assigned randomly to each plant and arranged in a split-plot design with nematode dosage as the main plot effect and method of application as the subplot effect. Treatments were applied to 8 plants within a row (block) and treated rows were replicated 5 times within each subplot (i.e., 8 plants $\times 4$ treatments $\times 5$ replicated $=160$ samples).

On the day following nematode application, 5 inoculated plants of each nematode treatment within a row (block) were selected randomly and infested with 20 eggs of $D$. radicum. Eggs of $D$. radicum were placed on small pieces of filter paper and gently washed onto the ground next to the base of each plant stem with a small stream of water. Eggs were then immediately covered with an $\approx 1-\mathrm{cm}$ layer of soil. The 3 remaining plants of each nematode treatment within a row (block) were not infested with eggs of $D$. radicum and were used to monitor nematode persistence and levels of natural infestation by $D$. radicum during the experiment.

To determine if nematodes persisted in the soil after application, soil samples were taken 4, 14, and $20 \mathrm{~d}$ after application (18 July, 28 July, and 3 August, respectively) in subplots that received subsurface applications of nematodes, and 1, 8, and $18 \mathrm{~d}$ after application (22 July, 29 July, and 8 August, respectively) in subplots that received surface applications of nematodes. On each date, a single soil core ( $2.5 \mathrm{~cm}$ diameter by $10 \mathrm{~cm}$ deep) was taken next to the stem of 3 plants (not infested with $D$. radicum) per treatment per block (i.e., 3 plants $\times 4$ treatments $\times 5$ blocks $=60$ soil samples per date or 15 soil samples per treatment per date). Each soil sample was thoroughly mixed and placed into a 0.5 -liter plastic cup. Ten greater wax moth larvae (Ja-Da Bait) were placed in each cup of soil and incubated in darkness for $2-6 \mathrm{~d}$ at $22^{\circ} \mathrm{C}$. After the incubation period, each cup was examined for nematode-infected larvae (larvae showing 
Table 1. Mean numbers of $D$. radicum recovered 5 wk after plants were infested with 5 eggs of $D$. radicum and treated with 4,000 infective juveniles of $S$. carpocapsae (25 strain), $S$. carpocapsae (NY001 strain), $\boldsymbol{H}$. bacteriophora (Oswego strain), S. feltiae (369 strain), or $S$. riobravus ( 355 strain) in the greenhouse

\begin{tabular}{lc}
\hline \hline Entomopathogenic nematode & D. radicum/plant \\
\hline Control (no nematodes) & $1.7 \pm 1.2 \mathrm{a}$ \\
S. carpocapsae (25) & $1.4 \pm 1.3 \mathrm{a}$ \\
S. carpocapsae (NY001) & $1.5 \pm 1.4 \mathrm{a}$ \\
H. bacteriophora (Oswego) & $1.4 \pm 1.3 \mathrm{a}$ \\
S. feltiae (369) & $0.6 \pm 1.0 \mathrm{~b}$ \\
S. riobrautus (355) & $1.6 \pm 1.4 \mathrm{a}$ \\
\hline
\end{tabular}

Numbers within a column are not significantly different if followed by the same letter ( $P=0.05$; Fisher LSD test).

typical symptoms of nematode infection coincident with the nematode that was applied or presence of infective juvenile nematodes) and the larvae counted.

On 4 August (subsurface applications) and 11 August (surface applications), 5 plants from each nematode treatment and 5 uninoculated plants (controls) were dug from each row in the field (5 plants $\times 5$ treatments $\times 4$ replicate $=100$ plants total on each date) and the roots were washed free of soil using a water spray. Roots were then rated for injury using the same procedure as described for the greenhouse experiments. Because many of the larvae of $D$. radicum had emerged as adults by the time samples were taken, $D$. radicum larvae and pupae were not counted. The effect of nematode dosage (main effect) and application method (subplot effect) on root damage indices was evaluated using ANOVA procedures appropriate to a split-plot design (SYSTAT 1992).

\section{Results and Discussion}

Greenhouse Experiments. In both experiment 1 and 2 (Tables 1 and 2 , respectively), $S$. feltiae caused a significant reduction in the number of $D$. radicum larvae (experiment $1, F=3.19$; $\mathrm{df}=5$, $20 ; P=0.028$; experiment $2, F=6.19$; $\mathrm{df}=4,20$; $P=0.002)$. Although infestations were relatively low (an average of 1.7 and $2.1 \quad D$. radicum per plant in the controls of experiment 1 and 2, respectively), plants treated with $S$. feltiae (369 strain) contained $64 \%$ (experiment 1) and $48 \%$ (experiment 2) fewer $D$. radicum than plants not treated with nematodes. Compared with uninoculated plants, S. carpocapsae (25 strain), S. carpocapsae (NY001 strain), S. riobravus (355 strain), and $H$. bacteriophora (Oswego strain) did not cause a significant reduction in the numbers of $D$. radicum. Root damage indices did not significantly differ $(F=0.38 ; \mathrm{df}=4,20 ; P=0.823$ ) among nematode treatments in experiment 2.

In experiment 3 (Table 3), significant differences were observed in the number of $D$. radicum recovered $(F=11.06 ; \mathrm{df}=6,30 ; P<0.001)$ and the root damage index computed $(F=4.61$; $\mathrm{df}=$
Table 2. Mean numbers of $D$. radicum recovered and mean root injury 4 wk after plants were infested with 5 eggs of $D$. radicum and treated with 3,000 infective juveniles of $S$. carpocapsae (NY001 strain), H. bacteriophora (Oswego strain), S. feltiae (369 strain), or S. riobravus ( 355 strain) in the greenhouse

\begin{tabular}{lcc}
\hline \hline Entomopathogenic nematode & $\begin{array}{c}\text { D. radicum/ } \\
\text { plant }\end{array}$ & Root injury \\
\hline Control (no nematodes) & $2.1 \pm 0.2 \mathrm{a}$ & $59.2 \pm 5.2 \mathrm{a}$ \\
S. carpocapsae (NY001) & $1.7 \pm 0.2 \mathrm{a}$ & $50.8 \pm 5.1 \mathrm{a}$ \\
H. bacteriophora (Oswego) & $1.7 \pm 0.2 \mathrm{a}$ & $48.3 \pm 6.8 \mathrm{a}$ \\
S. feltiae (369) & $1.1 \pm 0.1 \mathrm{~b}$ & $50.0 \pm 5.0 \mathrm{a}$ \\
S. riobravus (355) & $2.1 \pm 0.1 \mathrm{a}$ & $57.5 \pm 2.1 \mathrm{a}$ \\
\hline
\end{tabular}

Numbers within a column are not significantly different if followed by the same letter $(P=0.05$; Fisher LSD test). Root injury reported as mean root damage indices (Dapsis and Ferro 1982); $0=$ healthy plant, $25=$ superficial scarring, $50=$ deep feeding scars, $75=$ tap root severed, $100=$ plant dead.

$6,30 ; P=0.002)$ between plants receiving different nematode treatments. Plants treated with 30,000 infective juveniles of $H$. bacteriophora (Oswego strain) or plants treated with 3,000 or 30,000 infective juveniles of $S$. feltiae ( 27 strain) contained significantly fewer $D$. radicum than plants not treated with nematodes. Although not all nematode treatments significantly reduced the numbers of $D$. radicum recovered from the pots, the dosage of nematodes had a significant overall effect $(F=$ $4.90 ; \mathrm{df}=1,30 ; P=0.035$ ) on the number of $D$. radicum recovered. In general, the greatest dosages of nematodes caused the greatest reductions in numbers of $D$. radicum recovered from plants. Root injury was reduced by 30,000 (but not 3,000 ) infective juveniles of $S$. feltiae (27 strain). $S$. carpocapsae (NY001 strain), at dosages of either 3,000 or 30,000 infective juveniles per plant, caused no

Table 3. Mean numbers of $D$. radicum recovered and mean root injury 4 wh after plants were infested with 8 eggs of $D$. radicum and treated with 3,000 or 30,000 infective juveniles (U) of $S$. carpocapsae (NY001 gtrain), H. bacteriophora (Oswego strain), or S. feltiae (27 strain) in the greenhouse

\begin{tabular}{rcc}
\hline \hline $\begin{array}{c}\text { Dosage } \\
\text { (IJ/plant) }\end{array}$ & D. radicum/plant & Root injury \\
\hline \multicolumn{3}{c}{ Control (no nematodes) } \\
0 & $2.5 \pm 0.2 \mathrm{a}$ & $60.0 \pm 2.9 \mathrm{a}$ \\
& S. carpocapsae (NY001) \\
3,000 & $2.3 \pm 0.2 \mathrm{a}$ & $60.0 \pm 1.8 \mathrm{a}$ \\
30,000 & $2.0 \pm 0.2 \mathrm{ab}$ & $55.8 \pm 4.4 \mathrm{a}$ \\
\multicolumn{3}{c}{ H. bacteriophora (Oswego) } \\
3,000 & $2.1 \pm 0.4 \mathrm{ab}$ & $51.7 \pm 6.7 \mathrm{a}$ \\
30,000 & $1.1 \pm 0.2 \mathrm{~cd}$ & $50.8 \pm 3.7 \mathrm{a}$ \\
\multicolumn{3}{c}{} \\
3,000 & S. feltine (27) \\
30,000 & $1.4 \pm 0.3 \mathrm{bc}$ & $55.0 \pm 2.6 \mathrm{a}$ \\
& $0.5 \pm 0.1 \mathrm{~d}$ & $36.7 \pm 3.6 \mathrm{~b}$ \\
\hline
\end{tabular}

Numbers within a column are not significantly different if followed by the same letter ( $P=0.05$; Fisher LSD test). Root injury reported as mean root damage indices (Dapsis and Ferro 1982); $0=$ healthy plant, $25=$ superficial scarring, $50=$ deep feeding scars, $75=$ tap root severed, $100=$ plant dead. 
Table 4. Mean numbers of $D$. radicum recovered, mean root injury, and mean root and stem dry weight 4 wk after plants were infested with 8 eggs of $D$. radicum and treated with $0,100,1,000,10,000$, or 100,000 infective juveniles (IJ) of $S$. feltiae (27 strain) in the greenhouse

\begin{tabular}{rcccc}
\hline \hline $\begin{array}{c}\text { Dosage } \\
\text { (IJ/plant) }\end{array}$ & D. radicum/plant & Root injury, & Root dry weight, g & Stem dry weight, g \\
\hline 0 & $4.2 \pm 0.3 \mathrm{a}$ & $73.3 \pm 0.0 \mathrm{a}$ & $0.40 \pm 0.03 \mathrm{bc}$ & $2.21 \pm 0.17 \mathrm{~b}$ \\
100 & $4.4 \pm 0.2 \mathrm{a}$ & $72.2 \pm 1.5 \mathrm{a}$ & $0.38 \pm 0.03 \mathrm{c}$ & $2.22 \pm 0.10 \mathrm{~b}$ \\
1,000 & $3.4 \pm 0.1 \mathrm{~b}$ & $65.0 \pm 1.0 \mathrm{~b}$ & $0.49 \pm 0.04 \mathrm{~b}$ & $2.36 \pm 0.12 \mathrm{ab}$ \\
10,000 & $2.6 \pm 0.3 \mathrm{c}$ & $62.2 \pm 2.0 \mathrm{~b}$ & $0.45 \pm 0.02 \mathrm{bc}$ & $2.26 \pm 0.07 \mathrm{~b}$ \\
100,000 & $0.2 \pm 0.1 \mathrm{~d}$ & $32.8 \pm 2.0 \mathrm{c}$ & $0.65 \pm 0.07 \mathrm{a}$ & $2.47 \pm 0.08 \mathrm{a}$ \\
\hline
\end{tabular}

Numbers within a column are not significantly different if followed by the same letter ( $P=0.05$; Fisher LSD test). Root injury reported as mean root damage indices (Dapsis and Ferro 1982); $0=$ healthy plant, $25=$ superficial scarring, $50=$ deep feeding scars, $75=$ tap root severed, $100=$ plant dead.

significant reduction in numbers of $D$. radicum or the amount of root injury.

In experiment 4 (Table 4), nematode treatment caused significant differences in the number of $D$. radicum recovered $(F=216.82 ; \mathrm{df}=4,8 ; P<$ $0.001)$, root damage index $(F=133.93 ; \mathrm{df}=4,8$; $P<0.001)$, root dry weight $(F=14.10 ; \mathrm{df}=4,8$; $P=0.001)$, and stem dry weight $(F=4.59 ; \mathrm{df}=$ 4,$8 ; P=0.032$ ). Logarithmic increases in nematode dosage between 100 and 100,000 infective juveniles per plant caused significant linear reductions in the number of $D$. radicum recovered per plant $(r=0.97, P<0.0001)$ and damage caused to the roots by $D$. radicum larvae $(r=0.919, P<$ 0.0001 ). However, only the treatment where plants received the greatest dosage of nematodes (100,000 infective juveniles per plant) showed a significantly greater root and stem dry weight than the uninoculated treatment.

From these experiments, S. feltiae (27 and 369 strains) was identified as the strains (among those nematodes tested) most effective in reducing numbers of $D$. radicum developing on cabbage plants. Therefore, S. feltiae (27 strain) (S. feltiae [369 strain] was not available from Biosys after the ini-

Table 5. Mean root injury for plants that were naturally infested with $D$. radicum (natural population) or infested with 20 eggs of $D$. radicum (augmented population) and treated with $0,30,000,100,000$, or 200,000 infective juveniles (U) of $S$. feltiae ( 27 strain) using subsurface or surface application methods in the field

\begin{tabular}{rcc}
\hline \hline \multirow{2}{*}{$\begin{array}{c}\text { Dosage } \\
\text { (IJ/plant) }\end{array}$} & \multicolumn{2}{c}{ Root injury } \\
\cline { 2 - 3 } & $\begin{array}{c}\text { Augmented } \\
\text { population }\end{array}$ & $\begin{array}{c}\text { Natural } \\
\text { population }\end{array}$ \\
\hline & Subsurface \\
0 & $49.0 \pm 2.9$ & $33.3 \pm 6.5$ \\
30,000 & $37.3 \pm 4.5$ & $25.4 \pm 5.5$ \\
100,000 & $38.0 \pm 3.7$ & $46.7 \pm 5.0$ \\
200,000 & $30.5 \pm 7.3$ & $25.4 \pm 8.6$ \\
& Surface & \\
0 & $44.0 \pm 4.0$ & $25.0 \pm 4.6$ \\
30,000 & $37.0 \pm 4.9$ & $25.0 \pm 3.7$ \\
100,000 & $25.0 \pm 5.2$ & $1.0 .0 \pm 3.1$ \\
200,000 & $26.0 \pm 3.3$ & $1.3 .3 \pm 5.0$ \\
\hline
\end{tabular}

Root injury reported as root damage indices (Dapsis and Ferro 1982); $0=$ healthy plant, $25=$ superficial feeding scars, $50=$ deep feeding scars, $75=$ tap root severed, $100=$ plant dead tial tests) was selected for use in the field experiment.

Field Experiment. The application of S. feltiae (27 strain) to cabbage plants in the field had a significant $(F=6.93 ; \mathrm{df}=3,12 ; P=0.006)$ effect on root injury (Table 5). The amount of injury differed significantly $(F=22.31 ; \mathbf{d f}=1,12 ; P<$ 0.001 ) between plants that were infested artificially and those plants that were infested only by natural populations, suggesting that $D$. radicum populations were successfully augmented in the field. Also, the amount of root injury differed significantly between the methods of nematode application $(F=14.79 ; \mathrm{df}=1,32 ; P<0.001)$. Surface application was more effective than subsurface application in preventing damage to roots. In addition, a significant interaction $(F=4.01 ; \mathrm{df}=3,32$; $P=0.016$ ) between nematode dosage and method of application suggested that increased dosage was more effective in preventing injury by $D$. radicum when nematodes were applied to the soil surface than to the soil subsurface. Although significant differences in root injury occurred between nematode treatments, injury was noted in all treatments. Some plants were undoubtedly injured before the start of this experiment and this injury could not be separated from injury that occurred after nematode treatment. However, because more injury was observed on plants that were artificially infested with $D$. radicum, we suspect that some portion of the $D$. radicum population escaped nematode attack. The ineffectiveness of the nematode treatments to completely control $D$. radicum may have resulted from the limited susceptibility of early-instar $D$. radicum to entomopathogenic nematodes (Bracken 1990). Nevertheless, at the higher dosages, surface application was more effective than subsurface application in preventing injury caused by $D$. radicum. Because $D$. radicum eggs were placed on the soil surface near the root (where eggs of $D$. radicum are naturally laid), surface application may have deposited nematodes closer to $D$. radicum larvae than the subsurface application. The ability of the nematodes to remain active or persist after application can influence the effectiveness of the nematode treatments (Fuxa 1987). Surface application may leave a portion of 
Table 6. Mean number of $G$. mellonella larvae that died becuuse of infection hy entomopathogenic nematodes when 30 larvae of $G$. mellonella were exposed to soil samples taken next to plants treated with $0,30,000$, 100,000 , or 200,000 infective juveniles $(\mathbf{J})$ of Steinernema feltiae ( 27 strain) by subsurface or surface application in the field

\begin{tabular}{cccc}
\hline \hline \multirow{2}{*}{$\begin{array}{c}\text { Dose } \\
\text { (IJ/plant) }\end{array}$} & \multicolumn{3}{c}{ Mortality of G. mellonella } \\
larvae/30 \\
\cline { 2 - 4 } & Sample 1 & Sample 2 & Sample 3 \\
\hline \multicolumn{4}{c}{ Subsurface } \\
0 & 0.0 & 0.0 & 0.2 \\
30,000 & 26.0 & 26.2 & 18.2 \\
100,000 & 27.8 & 29.0 & 27.2 \\
200,000 & 25.0 & 28.0 & 27.8 \\
Mean & 19.7 & 20.9 & 18.3 \\
& & & \\
0 & Surface & 0.2 & 0.2 \\
30,000 & 0.8 & 25.8 & 15.0 \\
100,000 & 22.2 & 29.0 & 21.2 \\
200,000 & 23.8 & 28.0 & 24.0 \\
Mean & 26.4 & 1.8 & 15.1 \\
LSD (application) & 18.3 & 20.8 & 4.0 \\
LSD (dosage) & 5.7 & 2.1 & 5.6 \\
\hline
\end{tabular}

Samples 1, 2, and 3 were taken at 4, 14, and $20 \mathrm{~d}$ after subsurface application and 1,8 , and $18 \mathrm{~d}$ after surface application, respectively. LSD (application), least significant difference ( $\alpha=$ 0.05 ) between application means; LSD (dosage), least significant difference $(\boldsymbol{\alpha}=0.05$ ) between dosages within each application method.

infective juveniles on or near the surface, thus exposing them to desiccation (Womersley 1990) or the harmful effects of ultraviolet light (Gaugler and Boush 1978). In this study, nematodes persisted for $18-20 \mathrm{~d}$ and caused moderate to high (50-97\%) mortality of $G$. mellonella larvae at all dosages and application treatments (Table 6). Within each sample date, no significant differences in nematode persistence were detected between the different application treatments (sample $1, F$ $=0.68 ; \mathrm{df}=1,4 ; P>0.05$; sample $2, F=0.05$; $\mathrm{df}=1,4 ; P>0.05$; sample $3, F=4.95 ; \mathrm{df}=1$, $4 ; P>0.05$ ).

The greenhouse and field studies revealed that entomopathogenic nematodes, particularly S. feltiae (27 strain), are effective in reducing $D$. radicum larvae on cabbage. These pathogens, at the rates used in our field tests $(\approx 2.5-5$ billion/ha), may provide an alternative to the use of synthetic insecticides. Although nematode applications did not eradicate $D$. radicum populations in cabbage, treatments significantly reduced the amount of deep feeding scars caused by $D$. radicum that may have led to the loss of plants or a reduction in yield. Further studies need to be completed to determine an inexpensive and effective method for applying nematodes to cabbage plants in the field. Applications may be made at the time of transplanting by equipping mechanical transplanters with automatic and metered devices for injecting nematodes onto or into the soil around the base or root of each plant. These devices may be combined with fertilizer and water application equip- ment already present on many mechanical bare root transplanters.

\section{Acknowledgments}

We thank R. Brown, H. Dann, A. Fantauzzo, L. Ferris, D. Hoobler, A. Mahar, and J. Weyant for assisting in the greenhouse and field. This research was funded by Northeast Regional Integrated Pest Management Grant No. 93-34103-8425.

\section{References Cited}

Andaloro, J. T., K. B. Rose, A. M. Shelton, C. W. Hoy, and R. F. Becher. 1983. Cabbage growth stages. New York's Food and Life Sciences Bulletin 101, New York State Agricultural Experiment Station, Cornell University, Ithaca, NY.

Bracken, G. K. 1990. Susceptibility of 1st-instar cabbage maggot, Delia radicum (L.) (Anthomyiidae: Diptera), to strains of the entomogenous nematodes Steinernema feltiae. Filipjev, S. bibionis (Bovien), Heterorhabditis bacteriophora Poinar, and H. Heliothidis (Khan, Brooks, and Hirschmann). Can. Entomol. 122:633-639.

Dapsis, L. J., and D. N. Ferro. 1982. Crop loss assessment methods for the cabbage maggot (Diptera: Anthomyiidae) in cabbage. J. Econ. Entomol. 75: 777-780.

Fuxa, J. R. 1987. Ecological considerations for the use of entomopathogens in IPM. Annu. Rev. Entomol. 32: 225-251.

Gaugler, R., and G. M. Boush. 1978. Effects of ultraviolet radiation and sunlight on the entomogenous nematode, Neoaplectana carpocapsae. J. Invert. Pathol. 32: 291-296.

Georgis, R., G. O. Poinar, Jr., and A. P. Wilson. 1983. Practical control of the cabbage root maggot, Hylemia brassicae (Diptera: Anthomyiidae), by entomogenous nematodes. IRCS Med. Sci. Microbiol. Parasitol. Infect. Dis. 11: 322.

Gordon, R., T. L. Young, M. Cornect, and D. K. Hong. 1989. Effects of two insect growth regulators on the larval and pupal stages of the cabbage maggot (Diptera: Anthomyiidae). Environ. Entomol. 82: $1040-1045$.

Kaya, H. K., and R. Gaugler. 1993. Entomopathogenic nematodes. Annu. Rev. Entomol. 38: 181-206.

Matthews-Gehringer, D., and J. Hough-Goldstein. 1988. Physical barriers and cultural practices in cabbage maggot (Diptera: Anthomyiidae) management on broccoli and Chinese cabbage. J. Econ. Entomol. 81: $354-360$.

Schroeder, P. C., C. S. Ferguson, E. J. Shields, and M. G. Villani. 1994. Pathogenicity of rhabditid nematodes (Nematoda: Heterorhabditidae and Steinernematidae) to alfalfa snout beetle (Coleoptera: Curculionidae) larvae. J. Econ. Entomol. 87: 917-922.

Simser, D. 1992. Field application of entomopathogenic nematodes for control of Delia radicum in collards. J. Nematol. 24: 374-378.

SYSTAT. 1992. SYSTAT, version 5.2. Evanston, IL.

Welch, H. E., and L. B. Briand. 1961. Field experiment on the use of a nematode for the control of vegetable crop insects. Proc. Entomol. Soc. Ont. 91: $197-202$.

Womersley, C. Z. 1990. Dehydration survival and anhydrobiotic potential, pp. 123-124. In R. Gaugler and 
H. K. Kaya [eds.], Entomopathogenic nematodes for biological control. CRC, Boca Raton, FL.

Young, T. L., R. Gordon, and M. Cornect. 1987. Ef-

fects of several insect growth regulators on egg hatch and subsequent development in the cabbage maggot
Delia radicum (L.) (Diptera: Anthomyiidae). Can. Entomol. 119: $481-488$

Received for publication 3 January 1995; accepted 21 May 1996 